\title{
Impacto das Competências de Equipes sobre o Desempenho
}

\author{
Katia Puente-Palacios ${ }^{1}$ \\ Universidade de Brasília \\ Luana dos Santos Brito \\ Agência Nacional de Aviação Civil
}

\begin{abstract}
Resumo - As competências para o trabalho têm sido tradicionalmente compreendidas como atributos de indivíduos; entretanto, estudos mais recentes tornam pertinente defender a sua ocorrência como atributos coletivos. O objetivo deste estudo foi demonstrar que competências individuais podem transformar-se em competências coletivas e, nesse nível, predizer o desempenho da equipe. A testagem empírica foi realizada em 51 aeródromos brasileiros, totalizando 106 equipes (entre $3 \mathrm{e}$ 32 integrantes). Instrumentos respondidos pelos membros focaram nas competências enquanto os respondidos pelos lideres indagaram sobre o desempenho das equipes. Os resultados revelaram que as competências coletivas explicam aproximadamente $20 \%$ do desempenho das equipes. Disso depreende-se que as competências podem se manifestar como atributos coletivos que predizem resultados de equipes de trabalho.
\end{abstract}

Palavras-chave: competências, competências coletivas, desempenho de equipes

\section{Impact of Team Competencies on Performance}

\begin{abstract}
Job competences have been traditionally understood as individual properties. However, due to the increasing implementation of teams in organizations, is defended also that competences can be treated as a collective characteristic. The main goal of this study was demonstrate that competencies are collective properties and they act as predictors of team performance. The empirical study was undertaken with information collected from 51 Brazilian airports which tasks are organized on teams (106; 3 until 33 members). Team members offered information about competences, and leaders offered information about performance of teams. The results demonstrated that collective competencies explain around $20 \%$ of the performance. Based on those results, team competences are defended as collective characteristic that predict results of teams.
\end{abstract}

Keywords: skills, collective skills, shared cognitions, work teams.

O aumento da adoção de equipes nos ambientes de trabalho tem resultado no incremento de esforços de pesquisadores e gestores organizacionais para identificar os aspectos que favorecem o seu desempenho ou que permitem compreender os processos subjacentes ao seu funcionamento. Desde a perspectiva da Psicologia Organizacional o foco de interesse priorizado tem sido o sujeito, mesmo quando se busca entender o seu papel como membro de um contexto coletivo. Entretanto, nos últimos anos, a complexificação do cenário produtivo tem salientado a necessidade de mudar o foco de investigação e mirar nos agregados sociais, equipes, por exemplo, tornando elas as unidades de análise privilegiadas. Para compreender as equipes de trabalho é necessário tanto entender os comportamentos protagonizados por seus membros como também se deve buscar a compreensão da dinâmica que os integra e faz deles um coletivo.

A necessidade de mudança do nível de análise, entretanto, não constitui inquietação exclusiva dos teóricos interessados pelas equipes de trabalho. Discussões relativas ao foco ou nível de análise privilegiado podem ser vistas de longa data,

1 Endereço para correspondência: Campus Darcy Ribeiro, ICC Norte, Instituto de Psicologia. CEP: 70910-900. Brasília -DF. E-mail: kep. palacios@gmail.com por exemplo, na literatura que aborda o clima organizacional, como relatado por James et al. (2008). A mudança desse foco cobra maior importância se observamos que, na prática, tem ocorrido um acelerado aumento do uso de equipes como alternativa para a efetividade organizacional. Portanto, compreender adequadamente o seu funcionamento constitui um primeiro passo na direção do êxito na sua adoção. Assim, buscando contribuir com esse campo, foi testado um modelo preditivo no nível grupal ou meso, visando explorar e compreender o papel preditivo das competências das equipes de trabalho em relação à efetividade.

Para iniciar esse relato, cabe descrever o que são as equipes de trabalho. Elas constituem um conjunto de indivíduos caracterizado pelo fato de estar composto por pelo menos três membros, cujas tarefas e resultados são interdependentes, e precisam trabalhar e investir esforços buscando atingir uma meta comum. São demandados a compartilhar informações, e agir de modo coordenado e cooperativo (Cooke, Salas, Cannon-Bowers, \& Stout, 2000; Puente-Palacios \& González-Romá, 2013) buscando alcançar a efetividade no seu funcionamento.

Descrevendo o que deve ser entendido por efetividade, Hackman (2002), autor de produção profícua nesse campo 
do conhecimento, destaca que ela está composta por três critérios. O primeiro deles é o resultado do trabalho que não deve ser avaliado apenas a partir de um indicador duro ou evidência concreta, pois, segundo afirma, o aspecto central é a aceitação do produto (ou serviço) pelo cliente, seja ele interno a organização ou externo. Assim, o primeiro critério de efetividade da equipe é o desempenho conforme avaliado por quem o recebe (julgamento do desempenho ou avaliação julgamental).

O segundo critério diz respeito aos resultados da experiência de trabalho compartilhado. Nesse caso, a lógica subjacente é que a experiência do trabalho feito em conjunto deva favorecer a satisfação das expectativas dos membros antes que frustrá-las. Assim, resultados afetivos como a satisfação ou o comprometimento são indicadores adequados da efetividade da equipe.

Por fim, o terceiro critério faz referência à viabilidade ou sobrevivência da equipe, o que significa que a experiência de trabalho não pode culminar na sua desintegração, pois nesse caso, ainda que a tarefa tivesse sido realizada, haveria necessidade de investigar as causas que inviabilizaram a sua continuidade. Este conjunto de critérios, entretanto, não é proposto em substituição a qualquer indicador duro, mas defende-se a sua adoção como evidências adicionais.

Com relação à adoção de equipes por parte das organizações, observa-se que elas estão presentes nos mais diversos cenários, mas a sua presença é destacada em situações de risco, nas quais erros na execução da tarefa podem levar a consequências desastrosas ou quando o ambiente é altamente estressante ou exige decisões rápidas (Salas, Cooke, \& Rosen, 2008). Nesses contextos, as consequências do fracasso no desempenho podem estar associadas grandes prejuízos pessoais, organizacionais e ambientais. Em tais situações é esperado que o trabalho feito em equipe outorgue aos membros a vantagem de contar com diversas competências disponíveis, as quais ao serem compartilhadas podem incrementar a probabilidade de êxito da equipe.

A especificidade das equipes que trabalham em situações de risco tem sido objeto de discussão na psicologia e, autores como Kaplan, Laport e Waller (2013), descrevem se tratar de condições críticas entendidas como eventos que possuem baixa probabilidade de ocorrência, estão associadas a consequências de elevado impacto para o indivíduo, a equipe ou a organização, e se desenvolvem com baixa disponibilidade de tempo e elevada incerteza.

Discorrendo sobre os aspectos que afetam o funcionamento das equipes que operam em situações de crise, esses mesmos autores enfatizam que propriedades compartilhadas ou coletivas possuem um papel central. Entre essas, destacam a importância de afetos, conhecimentos, habilidades e atitudes, pontuando a sua centralidade para o êxito na realização da tarefa.

Dessas teorizações, depreende-se que a efetividade do desempenho das equipes é influenciada pelas características da equipe, entre as quais se destacam as competências, que devem ser compreendidas como um atributo coletivo. Entretanto, reconhece-se que boa parte da literatura que discute o papel das competências as assume como característica do indivíduo. Desse modo, a seção a seguir explora a sua compreensão como propriedade das equipes, ou seja, como característica do nível meso.

\section{Competências em equipes}

O ponto de partida das competências necessariamente é o indivíduo. Assim, é importante descrever a sua ocorrência no nível micro. As competências têm sido compreendidas como um conjunto de três elementos básicos: conhecimentos, habilidades e atitudes. O primeiro é descrito como aquilo que o indivíduo conhece e armazena em seus esquemas mentais para o entendimento do mundo, assim, diz respeito ao que o indivíduo conseguiu processar e reter de informação ao longo da sua vida. A habilidade, por outro lado, refere-se a saber realizar algo, e está ligada à capacidade do indivíduo de fazer uso produtivo do conhecimento que possui e transformar esse conhecimento em ação, de acordo com as exigências do contexto de trabalho (Brandão, Borges-Andrade, PuentePalacios, \& Laros, 2012; Durand, 2006). Dessa maneira, o conhecimento e a habilidade compõem a capacidade de um indivíduo para realizar uma ação.

O terceiro componente, as atitudes, está vinculado mais diretamente à esfera relacional do ambiente de trabalho. Podem ser descritas como tendência psicológica para avaliação que o sujeito faz sobre um objeto (ou fato), em relação ao qual tem algum grau de concordância ou discordância, o que faz com que exista uma intencionalidade da pessoa para realizar ou não determinada ação (Gilbert, Fiske, \& Lindzey, 1998). O reconhecimento da importância das atitudes ganhou espaço na psicologia, de tal sorte que atualmente não se prioriza somente o componente cognitivo (conhecimento) e o psicomotor (habilidade), pois se entende que as atitudes são também aspectos relevantes.

Focando no papel deste componente para o desempenho em situações de crise, Kaplan et al. (2013) trazem à tona a questão da afetividade positiva como fator determinante. Defendem que o trabalhador competente não é somente aquele que conhece bem a tarefa e sabe realizá-la com destreza. A esses atributos deve ser acrescentada a predisposição para desempenhá-la. Portanto, a dimensão atitudinal passou a ser compreendida como fator central para o entendimento do conceito de competência.

Uma definição atual, bastante difundida e aceita nos estudos sobre competências, é oferecida por Brandão et al. (2012) e leva em consideração os três elementos antes referidos: conhecimentos e habilidades (entendidos como capacidade), e atitude (entendida como intencionalidade). Para esses autores, competência seria a combinação sinérgica de conhecimentos, habilidades e atitudes manifestadas no desempenho profissional em determinado contexto organizacional - desempenho este que agrega valor à pessoa e à organização. Essa definição congrega as contribuições de importantes autores da área que discutem as competências e o seu papel no cenário de trabalho (Bruno-Faria \& Brandão, 
2003; Carbone, Brandão, Leite, \& Vilhena, 2006; Durand, 2006).

A aplicação desse conceito à gestão de organizações pode se dar em três níveis: macronível, mesonível e micronível (Bruno-Faria \& Brandão, 2003). No macronível, usualmente nomeado apenas como nível macro, a organização é considerada no seu todo. O suporte teórico mais proeminente para esta análise advém da Economia e da Administração ao tratar das competências associadas à competitividade das organizações, e ao discutir os atributos mínimos necessários ao seu funcionamento. $\mathrm{O}$ uso do termo competências nesse nível, contudo, é metafórico e diz respeito a características que diferenciam uma organização de outra e a tornam singular no mercado.

Quando se discute a competência no mesonível, por outro lado, o foco recai sobre as equipes ou outros segmentos intermediários (denominados nível meso). Apoiado em autores da área, Brandão (2009) salienta que, nas equipes de trabalho, ocorre a manifestação de competências coletivas, que não resultam da simples soma das competências individuais dos membros, mas constituem um arranjo ou combinação sinérgica das competências individuais que se transformam e delas emerge uma competência coletiva. A psicologia Organizacional tem dado alguns passos tímidos na explicação teórica da manifestação de competências nesse nível, descrevendo os atributos teóricos que as caracterizam, assim como as demandas empíricas para o seu estudo. Por fim, no micronível, os indivíduos são considerados o foco de análise e, nesse caso, a Psicologia Organizacional e do Trabalho constitui uma das principais representantes teóricas ao priorizar o estudo de características relativas ao indivíduo (nível micro), na tentativa de elucidar as relações entre a aprendizagem, a competência individual e outros comportamentos ocorridos no âmbito das organizações, como o desempenho do trabalhador.

Neste manuscrito, como antes manifestado, o foco recai nas equipes de trabalho, consideradas representantes do nível meso. As competências da equipe constituem um tipo de atributo grupal, que surge quando os membros das equipes compartilham conhecimentos, habilidades e atitudes (competências), o que resulta na construção de um arranjo coletivo. A esse respeito Puente-Palacios e González-Romá (2013) destacam a centralidade da experiência do trabalho feito em grupo para o surgimento de compreensões e interpretações similares (cognições), tanto sobre as tarefas que a equipe executa, como sobre o meio em que a equipe opera. Esse compartilhamento de visões sobre o mundo que os cerca recebe a denominação genérica de cognições compartilhadas e a importância da sua ocorrência está, segundo esses autores, no poder que têm de afetar o comportamento e o desempenho da equipe.

Embora o termo compartilhado possua diversos significados (Cannon-Bowers \& Salas, 2001), no caso das competências de equipes, o sentido dado é o de similaridade no domínio das competências necessárias para a realização das tarefas. Logo, a defesa da existência desse atributo no nível meso, assim como o seu poder preditivo, parte da compreensão de que certos conhecimentos, habilidades e atitudes precisam caracterizar a equipe como um todo, o que significa defender que todos os membros deverão apresentar algum grau de domínio dessas competências. Portanto, não seria pertinente falar em competências da equipe se apenas um membro fosse detentor do atributo referido.

As competências para o trabalho em equipes podem ser diversas. Cannon-Bowers, Tannenbaum, Salas e Volpe (1995) discriminam as que fazem referência à tarefa daquelas relacionadas à manutenção do grupo social. Esses autores ainda defendem que o êxito no desempenho resulta do domínio de competências voltadas para a execução da tarefa, mas também daquelas relativas à manutenção de relações harmoniosas, as quais favorecem os intercâmbios e trocas entre os membros, assim como as atividades de coordenação e cooperação, consideradas ações vitais para o trabalho realizado por pessoas trabalhando juntas.

Desse modo, para a realização do estudo relatado neste manuscrito, as competências (compartilhadas ou similares) de equipes englobam tanto as chamadas competências de tarefas, como as denominadas competências relacionais. Embora seja defendida similaridade dessas competências, entende-se que não estarão presentes em igual intensidade, em todos os membros, pois certa margem de diversidade é esperada.

Em relação às consequências da presença de competências compartilhadas, pautada na similaridade, é esperado que favoreçam o desempenho. Estudiosos das equipes como Cannon-Bowers e Salas (2001) defendem que grupamentos em que seus integrantes compartilham visões similares sobre o trabalho, gastam menos tempo com ações de negociação e comunicação, uma vez que possuem formas similares de compreender as tarefas, o cenário e a partir disso, têm maior possibilidade de diagnosticar o problema enfrentado de maneira convergente e reagir com maior agilidade e presteza. Rentsch e Woeher (2004) assim como Fiore e Schooler (2004), sustentados em achados de pesquisadores deste campo e teorizações diversas, apontam que, de maneira geral, as cognições de equipes (compartilhadas) têm demonstrado poder preditivo relevante em relação a resultados como efetividade, atividades de treinamento em equipes militares, comunicação, escolha de alternativas para solução de problemas, dentre outros.

Com relação aos estudos empíricos realizados no nível meso, e que sustentam as relações antes defendidas, pode ser mencionado o trabalho de Hauland (2008), responsável por evidenciar que competências das equipes, operacionalizadas em termos de atividades de planejamento para monitoramento de um determinado campo visual, estiveram associadas a melhor desempenho avaliado em temos de agilidade de resposta. Da mesma forma, Hertel, Konradt e Voss (2007), buscando evidencias de validade de uma medida de competências de equipes virtuais, revelaram, além da adequação do instrumento proposto, correlação entre as competências coletivas mapeadas e a efetividade das equipes. Já Bole, Fink e Prašnikar (2016) investigaram especificamente o papel preditivo das competências de equipes com foco no cliente, em uma grande amostra (1.500 equipes de projetos), e constataram associação positiva entre essas competências e o desempenho das equipes. Desse modo, o papel preditivo das competências da equipe em relação aos resultados dessas unidades de desempenho conta com algumas evidências importantes trazidas pela literatura 
internacional. Já no que diz respeito à literatura nacional, constatou-se ausência de estudos empíricos dessa natureza que, focando em competências coletivas ou do nível meso, buscasse fazer alguma associação com resultados dessas células de trabalho, fato que evidencia a necessidade de avanço nos estudos desse campo.

Com relação ao processo mediante o qual propriedades do nível micro dão lugar ao surgimento de características do nível meso, Kozlowski e Chao (2012) esclarecem que tanto o conhecimento como a aprendizagem ocorrem necessariamente no nível do indivíduo. Mas, a partir de processos de interação social, há uma expansão e, com o transcurso do tempo, surgem conhecimentos e saberes próprios da equipe. Essa mudança de nível é conhecida sob a denominação de processo de emersão e autores como Klein e Kozlowski (2000) apontam que se origina de conhecimentos, habilidades e atitudes dos sujeitos, que ao ser articuladas socialmente (entre os sujeitos) resultam na manifestação de atributos coletivos.

A ocorrência dos processos de emersão não segue um percurso único. Chan (1998) propõe cinco formas possíveis, cada uma das quais possui uma natureza diferenciada dependendo das peculiaridades do fenômeno focado. No caso das competências de equipes, e tendo defendido o seu surgimento a partir a similaridade com que se manifestam no nível individual, o modelo que melhor as representa é o chamado Modelo de Dispersão. Apesar da denominação, esse modelo sustenta-se na existência de semelhanças do atributo, evidenciadas mediante a constatação empírica da presença de escassas diferenças interindividuais (baixa dispersão, portanto).

Além de propor um modelo compreensivo do fenômeno, o autor apresenta a métrica necessária para a investigação empírica de sorte a alinhar teoria e método. Assim, Chan (1998) destaca que para a testagem do modelo de dispersão não é suficiente somar escores individuais buscando construir um escore coletivo. É necessário investigar a magnitude da similaridade do atributo entre os membros do grupo, sendo possível concluir que se trata de propriedade compartilhada e não de um mero agregado.

A partir das considerações teóricas apresentadas, relativas tanto à efetividade das equipes como às competências compartilhadas, definiu-se como objetivo deste estudo mensurar o poder preditivo de duas variáveis antecedentes: o domínio de competências dos membros da equipe e o compartilhamento dessas competências (nível meso), na explicação da efetividade de equipes, evidenciada a partir de dois indicadores, sendo eles uma avaliação julgamental e um indicador objetivo. A investigação empírica contempla equipes que desempenham as suas atividades em condições críticas de trabalho (ou em situações de risco), pois se considera que nelas é mais saliente a contribuição de competências do nível meso.

Os resultados de pesquisas empíricas visitadas permitem levantar algumas hipóteses descritas a seguir: H1 - Quanto maior o domínio de competências por parte dos membros, melhor o desempenho da equipe; H2 - O maior domínio coletivo (compartilhamento) de competências (do nível meso) está associado ao melhor desempenho da equipe (H2); e, H3 - Competências coletivas (compartilhadas) explicam melhor o desempenho que as competências dos membros (H3).

\section{Método}

Tendo em vista a especificidade defendida para as tarefas das equipes - em situações de risco-, considerou-se pertinente descrever a natureza das tarefas e das células das quais os dados foram levantados. Trata-se de equipes que atuam quando ocorrem acidentes aeronáuticos, sendo que a sua tarefa é de salvamento e combate a incêndio em aeródromos. Manuseiam equipamentos de elevado custo e alta complexidade técnica e de operação, e as consequências do erro no desempenho envolvem riscos pessoal, institucional e ambiental, sendo que pode levar até a perda de vidas humanas. Adicionalmente, o desempenho dessas equipes deve ocorrer observando rígidas normas e regras locais, nacionais e internacionais que definem, inclusive, o tempo máximo de execução das tarefas, o que justifica que sejam consideradas em situações de crise.

\section{Participantes}

Para a realização da pesquisa, foram contatados 51 aeródromos brasileiros, onde labora um total de 184 equipes de serviço. Foram enviados 2.040 questionários e desses 1.209 foram devolvidos, atingindo uma taxa de retorno de $59,26 \%$. Desse total, 13 questionários foram retirados por apresentarem mais de $50 \%$ das respostas em branco, de modo que a amostra que deu origem às análises foi composta por 139 equipes, compreendendo 1.196 respondentes.

A composição dessas equipes era de 3 a 32 membros e a maioria dos participantes era do sexo masculino $(95,7 \%)$, com idade média de 35 anos $(\mathrm{DP}=8,48)$. $\mathrm{O}$ tempo médio de serviço desses profissionais era de 4 anos $(\mathrm{DP}=5,67)$ e, a maioria $(51,1 \%)$ tinha ensino médio completo.

Cada equipe possui um líder (chefe) que foi a pessoa responsável por fornecer informações quanto à variável consequente do estudo. A pesquisa contou, desse modo, com a participação de 52 chefes que avaliaram suas respectivas equipes quanto ao desempenho demonstrado. Ainda deve ser mencionado que alguns desses líderes coordenavam mais do que uma equipe e, por essa razão, forneceram informações sobre o desempenho de todas as que estavam sob seu comando.

\section{Procedimento de Coleta de Dados}

O convite para participar na pesquisa foi enviado por meio de e-mail institucional aos respondentes e foi esclarecida a finalidade do estudo. Entretanto, o envio do questionário ocorreu por meio físico (em papel) e, após serem respondidos, foram devolvidos por correio regular à pesquisadora. Os questionários continham uma carta de apresentação em que o teor da pesquisa era explicitado, assim como o caráter voluntario da participação. Explicava-se também que o anonimato estava garantido, que as respostas fornecidas 
seriam tratadas com sigilo e que não haveria qualquer consequência danosa para o respondente que decidisse participar ou não. Desse modo, os princípios éticos que regem as pesquisas com serem humanos foram respeitados.

\section{Instrumentos}

Para levantar as informações relativas às variáveis contempladas no estudo foram utilizados questionários com evidências psicométricas de validade já estabelecidas e foram obtidos dados de fonte secundária (registros da empresa). Os membros das equipes responderam individualmente a Escala de Competências que foi desenvolvida para esta pesquisa. A medida está composta por 25 itens que descrevem competências coletivas, e devem ser respondidos mediante uma escala do tipo Likert de domínio, de 5 pontos $(0=$ não domina; 4 = domina completamente). Os enunciados das perguntas têm como referente a equipe a que os membros pertencem. A medida possui estrutura interna organizada em três fatores, sendo o primeiro voltado para as Competências Relacionais e de Trabalho (F1- 15 itens; $\alpha=0,93 ; r$ itemtotal $=0,67$; p. ex., Os membros da minha equipe têm bom relacionamento interpessoal); o segundo aborda as Competências Instrumentais (F2- sete itens; $\alpha=0,81 ; r$ item-total $=0,55 ;$ p. ex., Os membros da minha equipe conhecem o conceito do exercício de tempo-resposta), e o terceiro tem foco na Obediência às Normas (F3- três itens; $\alpha=0,81 ; r$ item-total $=0,67$; p. ex., Os membros da minha equipe conhecem as características das aeronaves que mais operam no aeródromo).

A escala de Avaliação de Desempenho da equipe, desenvolvida por Puente-Palacios, Martins e Palumbo (2016), foi respondida pelo líder. A medida está composta por nove itens atrelados a uma escala de respostas do tipo Likert de concordância, que varia de 1 a 5 . Possui estrutura unifatorial e demonstra índices de consistência interna satisfatórios ( $\alpha 0,83 ; r$ item-total de 0,55$)$. O foco dos enunciados das perguntas recai no desempenho coletivo da equipe (p. ex.: Os prazos de trabalho estabelecidos são cumpridos por esta equipe).

Como critérios concretos do desempenho das equipes (indicadores duros) foram obtidas informações de fonte secundária, contidas no sistema de registro informatizado da empresa. Trata-se de dados relativos aos tempos-resposta das equipes participantes da pesquisa, obtidos em exercícios de simulação de tarefas, os quais fazem parte das estratégias de operação de todos os aeródromos brasileiros e cuja execução periódica obedece a normas e legislações específicas do setor de aviação. A unidade de medida do tempo-resposta é segundos.

\section{Análise de Dados}

A análise de dados foi organizada de sorte a viabilizar, em primeira instância, a investigação da emersão de competências cuja informação foi recolhida no nível individual. Assim, buscou-se evidenciar a sua transformação em atributo relativo às equipes, ou do nível meso. Para tanto, foi utilizada a análise dos desvios médios em relação à mediana $\left(\mathrm{AD}_{\mathrm{Md}}\right)$, que informa, para cada equipe, a magnitude da variância intragrupal. A seguir, foi calculada uma Anova (one way), estratégia de análise de variância que compara os padrões de respostas de diversos grupos ou, neste estudo, as equipes dos aeródromos. Os resultados desta análise, quando significativos, ao ser lidos junto com os fornecidos pelo $\mathrm{AD}_{\mathrm{Md}}$ (dentro dos valores críticos), permitem concluir a respeito da ocorrência da emersão. De posse dessas informações, foi construído o modelo preditivo no nível meso e as hipóteses testadas mediante um modelo de regressão organizada em dois passos. As análises dos dados foram realizadas na versão 21 do programa Statistical Package for the Social Sciences (SPSS).

\section{Resultados}

Uma vez que as informações da variável antecedente (competências) foram recolhidas no nível individual, mas defende-se à sua ocorrência no nível meso, a primeira etapa das análises focou na testagem da emersão. Para tanto foram seguidos dois procedimentos. No primeiro deles, analisou-se a variabilidade de respostas dos membros, em cada equipe, mediante o cálculo dos desvios médios $\left(\mathrm{AD}_{\mathrm{Md}}\right)$ que informa a magnitude do desvio do conjunto de respostas de cada grupamento. A sua interpretação está atrelada a um valor crítico que releva o máximo de discrepância tolerado. Esse valor crítico considera a amplitude da escala de respostas e sustenta-se na relação de c/6 (onde 6 é uma constante). Burke e Dunlap (2002) esclarecem que o termo "c" indica a amplitude da escala que no caso da avaliação de competências, neste estudo, foi de cinco pontos o que resulta em um valor crítico de 0,83 . Esse valor significa que 0,83 é o máximo de afastamento médio tolerado em uma escala de 5 pontos para que se conclua que os membros de uma equipe têm visões similares sobre o assunto indagado; ou seja, compartilham competências. Equipes com valores de $\mathrm{AD}_{\mathrm{Md}}$ superiores ao valor crítico devem ser eliminadas de análises posteriores, pois não demonstram a ocorrência de emersão antes defendida.

A aplicação desse critério foi feita para os três fatores da escala de competências e todas as equipes que superaram o valor crítico do $\mathrm{AD}_{\mathrm{Md}}$, em qualquer um deles, foram eliminadas do banco de dados para as análises subsequentes. $\mathrm{Na}$ amostra deste estudo, cinco equipes, de 139 (1.136 membros), mostraram não possuir percepções compartilhadas sobre o domínio de competências.

O segundo passo na investigação da emersão de competências se deu pela a realização de uma análise de variância, mediante uma Anova (one way). Com a aplicação desse procedimento foram comparados os padrões de resposta das equipes participantes do estudo. Os resultados, ao serem significativos para todos os fatores da medida de competências, corroboraram os indícios antes dados pelo $\mathrm{AD}_{\mathrm{Md}}$ e permitiram afirmar que as competências levantadas neste estudo são, de fato, atributos das equipes, pois foram observadas similaridades intensas nas respostas dadas pelos membros das mesmas equipes e, concomitantemente, foram identificadas diferenças estatisticamente significativas ao 
comparar padrões de respostas por equipes. A Tabela 1 resume os achados relativos à verificação da ocorrência do processo de emersão de competências.

Uma vez constatada a pertinência de compor escores grupais, por equipe, sobre competências para o trabalho, deu-se início a testagem do modelo de predição. Nele, buscou-se evidenciar o poder explicativo das competências compartilhadas (ou do nível meso) em relação ao desempenho de equipes de trabalho, capturado tanto pela avaliação feita pelo líder da equipe, como por indicador duro obtido dos registros da empresa em termos de tempos-resposta das equipes, nos exercícios de simulação.

A construção do modelo preditivo iniciou com a verificação dos pressupostos estatísticos da análise a ser utilizada. Assim, investigou-se a presença de casos (equipes) extremos multivariados, mediante o cálculo da distância Mahalanobis e os 12 nessa condição foram retirados do banco de dados, em decorrência da sua possível influência para as análises pretendidas.

O segundo passo foi a verificação da multicolinearidade, seguindo os delineamentos propostos por Menard (1995). Uma vez que houve mais respostas de líderes que indicadores duros, as testagens foram realizadas com bancos de tamanhos diferentes, sendo 106 equipes para o julgamento do desempenho e 64 para a testagem do indicador duro. A realização dessa análise revelou comportamento inadequado do F2 - competências dos membros, para a predição do julgamento do desempenho, e de F1 e F2 - competências dos membros, para o modelo preditivo do tempo-resposta. Assim, esses fatores, tratados como variáveis antecedentes precisaram ser excluídas na fase de construção dos modelos de predição correspondentes.

A seguir, realizou-se a inspeção da matriz de correlações entre as variáveis dos modelos, o que revelou padrões de associação diferenciados, quando as competências foram tratadas como atributos dos membros (agregados via cálculo da média aritmética) e quando foram tratados como atributos coletivos (quando o indicador é o valor do $\mathrm{AD}_{\mathrm{Md}}$ ), conforme mostra a Tabela 1 .
Os dados contidos na tabela evidenciam a existência de correlações significativas com escassa variação se comparados os resultados dos dois bancos de dados antes mencionados (106 e 64 equipes). Esse fato torna pertinente concluir quanto à existência de associação entre as variáveis do estudo, mesmo quando um número menor de equipes foi incluído. Com relação à intensidade, a correlação de valor mais elevado foi a estabelecida entre o F2- I (Competências Instrumentais Individuais) e o mesmo fator de competências da equipe (F2-C), o que corrobora os resultados da análise de multicolinearidade antes relatada.

Um segundo aspecto ao analisar na matriz de correlações é a existência de associações significativas entre as variáveis antecedentes e critério do estudo. Essa inspeção evidenciou a ausência de correlação significativa entre a variável critério tempo-resposta e as variáveis antecedentes, fato que contradiz as expectativas teoricamente sustentadas quanto ao poder preditivo das competências, sejam elas individuais ou coletivas. Embora esses dados sejam indícios iniciais da falta de associações, o modelo proposto defende o poder preditivo do conjunto de fatores que compõem as competências. Desse modo, tomou-se a decisão de dar continuidade à construção do modelo conforme inicialmente previsto.

A testagem dos modelos de regressão para julgamento feito sobre o desempenho e tempo-resposta foi realizada, em ambos os casos, em duas etapas, utilizando o método de entrada forçada (Enter). No primeiro passo foi introduzido o conjunto de variáveis antecedentes que expressam o compartilhamento das competências (coletivas - de equipe), as quais foram operacionalizadas pela magnitude do desvio médio das respostas em relação à mediana do grupo $\left(\mathrm{AD}_{\mathrm{Md}}\right)$. Assim, valores menores nessa variável evidenciam menores desvios (ou maior similaridade existente na equipe). $\mathrm{O}$ segundo passo consistiu na entrada do conjunto de variáveis que representavam as competências dos membros da equipe, as quais foram operacionalizadas pela média aritmética por equipe, em cada fator.

Os resultados da predição do desempenho, segundo julgamento feito pelo líder, revelam que o conjunto de competências de equipe (coletivas) predizem ao redor de

Tabela 1. Correlações entre as variáveis do estudo

\begin{tabular}{|c|c|c|c|c|c|c|c|c|c|c|}
\hline & \multicolumn{2}{|c|}{$\mathrm{AD}_{\mathrm{Md}}$} & \multirow[b]{2}{*}{$\mathrm{F}$} & \multirow[b]{2}{*}{ F2-I } & \multirow[b]{2}{*}{ F3-I } & \multirow[b]{2}{*}{ F1-C } & \multirow[b]{2}{*}{ F2-C } & \multirow[b]{2}{*}{ F3-C } & \multirow[b]{2}{*}{ D-J } & \multirow[b]{2}{*}{ T-R } \\
\hline & $X$ & DP & & & & & & & & \\
\hline F1-I & 0,33 & 0,19 & 3,49 & $\begin{array}{c}0,76 \\
(0,76)\end{array}$ & $\begin{array}{c}0,79 \\
(0,79)\end{array}$ & $\begin{array}{c}-0,88 \\
(-0,92)\end{array}$ & $\begin{array}{c}-0,75 \\
(-0,75)\end{array}$ & $\begin{array}{c}-0,67 \\
(-0,73)\end{array}$ & 0,29 & $(-0,11)$ \\
\hline F2-I & 0,20 & 0,14 & 2,83 & & $\begin{array}{c}0,74 \\
(0,72)\end{array}$ & $\begin{array}{c}-0,62 \\
(-0,68)\end{array}$ & $\begin{array}{c}-0,92 \\
(-0,93)\end{array}$ & $\begin{array}{c}-0,51 \\
(-0,59)\end{array}$ & 0,23 & $(-0,13)$ \\
\hline F3-I & 0,40 & 0,20 & 3,16 & & & $\begin{array}{c}-0,72- \\
0,76)\end{array}$ & $\begin{array}{c}-0,75 \\
(-0,76)\end{array}$ & $\begin{array}{c}-0,76 \\
(-0,76)\end{array}$ & 0,22 & $(-0,13)$ \\
\hline F1-C & -- & -- & -- & & & & $\begin{array}{c}0,71 \\
(0,75)\end{array}$ & $\begin{array}{c}0,80 \\
(0,85)\end{array}$ & $-0,30$ & $(0,11)$ \\
\hline F2-C & -- & -- & -- & & & & & $\begin{array}{c}0,64 \\
(0,69)\end{array}$ & $-0,24$ & $(0,14)$ \\
\hline F3-C & -- & -- & -- & & & & & & $-0,23$ & $(0,04)$ \\
\hline
\end{tabular}

Notas. Correlações significativas $(p<0,05)$ acima de 0,21 . Todos os valores F significativos. Entre parêntesis - correlações no banco composto por 64 equipes. F1- Competências Relacionais ou de Trabalho; F2- Competências Instrumentais; F3 Obediência às Normas; I - Individuais; C- Coletivas; D-J - Desempenho Julgamental; T-R Tempo-resposta. 
$22 \%$ do desempenho $\left(\mathrm{R}^{2}=0,22, \mathrm{p}<0,001\right)$. A inserção das competências dos membros, no passo dois, não resultou em acréscimo significativo no poder explicativo oriundo dessas variáveis. Paralelamente, a análise do efeito individual de cada fator evidencia que o Fator 1, que condensa as competências relacionais ou de trabalho, se associa de maneira significativa e direta com a variável critério. Ou seja, essas competências explicam uma porção significativa do desempenho quando esse é avaliado pelo líder da equipe ( $\beta=-0,42, p<0,01)$ e, embora hipóteses sobre o papel independente de cada fator não tenham sido levantadas, cabe interpretar o resultado identificado.

Todavia, considerando o sinal negativo dessa relação, a associação referida significa que equipes que compartilham mais as competências relacionais e de tarefa (ou possuem baixa discrepância) têm seu desempenho mais favoravelmente avaliado pelos chefes que os lideram. A tabela a seguir apresenta resumidamente os resultados desse modelo preditivo.

Tabela 2. Predição do desempenho julgamental

\begin{tabular}{lc}
\hline Variável antecedente & $\boldsymbol{\beta}$ \\
Passo 1 & $-0,42^{*}$ \\
\hline Fator 1- C (Competências Relacionais ou de Trabalho) & 0,38 \\
Fator 2- C (Competências Instrumentais) & $-0,10$ \\
Fator 3- C (Obediência às Normas) & $22,3 \% * *$ \\
$\Delta \mathrm{R}^{2}$ & \\
\hline Passo 2 & 0,40 \\
\hline Fator 1- I (Competências Relacionais ou de Trabalho) & 0,11 \\
Fator 3- I (Obediência às Normas) & $2,1 \%$ \\
$\Delta \mathrm{R}^{2}$ & $24,4 \% * *$ \\
$\mathrm{R}^{2}$ & \\
\hline
\end{tabular}

Nota. ${ }^{*} p<0,05 ;{ }^{*} p<0,001 ; \mathrm{C}$ - Competências Coletivas; I-

Competências Individuais.

Conforme dados apresentados da Tabela 2, é possível afirmar que a hipótese $\mathrm{H} 2$, segundo a qual - quanto maior o compartilhamento de competências (competências coletivas, um tipo de cognição compartilhada), melhor o desempenho da equipe - e a hipótese $\mathrm{H} 3$ - as competências coletivas explicam melhor o desempenho do que o domínio das competências individuais - foram corroboradas.

Já em relação à hipótese $\mathrm{H} 1$ - quanto maior o domínio de competências dos membros (agregadas) melhor o desempenho da equipe - os resultados do modelo construído não permitiram a sua confirmação, na amostra com a que esta pesquisa foi realizada. Contudo, uma vez que a testagem do seu poder de predição ocorreu no segundo passo, após a inserção das competências coletivas, questiona-se quanto a ausência de efeito decorrer da ordem de entrada. Para verificar essa possibilidade, foi testado um modelo alternativo, de passo único, em que os três fatores das competências individuais foram inseridos conjuntamente. Adotando esse procedimento, foi alcançada significância estatística, porém, com um poder preditivo de baixa magnitude (aproximadamente 6\%).

Os dados obtidos desse conjunto de análises tornam pertinente afirmar que as competências coletivas possuem maior poder de predição se comparado com o apresentado pelas competências dos membros (agregadas). Em relação a estas últimas, dado o escasso poder de predição, podem ser consideradas preditores pobres do desempenho e reconhecese que, na pesquisa realizada, o sustento para a primeira hipótese (H1) é frágil.

Dando continuidade as análises, um segundo modelo de predição foi construído buscando predizer o desempenho capturado mediante o critério de tempo-resposta (em segundos) das equipes. Os mesmos passos foram seguidos, desse modo, os três fatores das competências coletivas foram introduzidas no passo 1 e os três das competências individuais acrescentados no passo 2 . Os resultados demonstram que as variáveis antecedentes, tanto do passo 1, quanto do passo 2, não demonstraram estar associadas ao desempenho quando esse foi avaliado pelo critério de tempo-resposta. Assim, os resultados encontrados revelam que com a amostra de dados do presente estudo não foi possível identificar qualquer poder explicativo das competências individuais ou coletivas em relação ao indicador duro de desempenho das equipes. Todavia, a ausência de relações é atribuída à tipicidade das esquipes estudadas e ao critério de desempenho adotado, e não à falta de associação entre as variáveis. Por essa razão, uma análise cuidadosa do significado dessa ausência de relação é apresentada a seguir, buscando alertar o leitor quanto a cuidados que devem ser tomados ao escolher o critério indicador das variáveis estudadas.

Tendo em vista o conjunto de achados resultantes da realização do estudo ora descrito, a próxima seção discute as suas derivações e implicações à luz da literatura da área com o intuito de contribuir com a construção do conhecimento sobre este campo e, de maneira específica, favorecer a melhor compreensão do papel das competências, quando tratadas como atributo das equipes.

\section{Discussão}

O objetivo central do estudo relatado neste artigo foi identificar o poder preditivo das competências de equipes de trabalho. A premissa teórica fundamental em que se sustenta estabelece que as competências coletivas são mais que um mero agregado de competências dos membros, pois elas devem ser compartilhadas para que de fato caracterizem o nível meso, representando, desse modo, um atributo da equipe. A pesquisa empírica realizada mostrou associação entre algumas das competências coletivas e critérios de desempenho. Entretanto, também se observou ausência de algumas das relações esperadas. Tanto as observadas como as que não foram identificadas precisam ser exploradas buscando compreender o seu significado e o que elas oportunizam para o avanço do conhecimento científico e a gestão de equipes no mundo do trabalho.

Em primeiro lugar, a pertinência de tratar as competências como um atributo coletivo foi demonstrada a partir do comportamento dos dados recolhidos, fato que coaduna com a teoria da área. Embora os membros das equipes tenham respondido individualmente o instrumento que avalia as competências, o fenômeno eliciado mediante as perguntas contidas no instrumento mostrou ser, de fato, 
coletivo. Quanto ao uso dessa estratégia operacional, PuentePalacios e Portmann (2009) afirmam que as medidas com foco no coletivo devem levar o participante a pensar no grupo e não em si mesmo na hora de oferecer as respostas. O comportamento dos dados evidencia a pertinência do uso dessa estratégia, pois do total de equipes consideradas para as análises de dados, apenas cinco, de 139 (3,59\%), mostraram que seus integrantes tinham visões divergentes quanto às competências que o coletivo possui. Ou seja, a grande maioria de respondentes forneceu respostas similares, o que dá suporte a estratégia de coleta de dados adotada.

Esses resultados iniciais permitem tecer algumas conclusões adicionais. Em primeiro lugar, uma conclusão de natureza teórica é que as equipes possuem competências que são mais do que um mero agregado de conhecimentos, habilidades e atitudes dos seus integrantes, achado esse que é consonante com as afirmações feitas por Brandão (2009) quanto à legitimidade de tratar as competências como atributo coletivo. Desse modo, entende-se que da mesma maneira que indivíduos desenvolvem competências úteis para o seu desempenho, equipes passam por um processo similar e também desenvolvem competências coletivas que agregam valor ao seu trabalho e contribuem com a organização.

Uma segunda derivação feita a partir dos achados antes mencionados refere-se ao fato das competências coletivas não serem adequadamente representadas mediante simples operações de adição de respostas individuais. Essa prática desconsidera a demanda de compartilhamento que subjaz a compreensão delas enquanto característica das equipes. Portanto, constatar a magnitude do compartilhamento é condição imprescindível para o pesquisador interessado em acessar competências coletivas (ou da equipe) alinhando, desse modo, a operacionalização à base teórica na qual se estabelece que as competências de equipes são atributos compartilhadas.

Quanto às hipóteses levantadas, o estudo realizado buscou investigar três possíveis associações entre as variáveis participantes. A primeira hipótese (H1) estabelece que as competências dos membros predizem o desempenho da equipe. Os resultados obtidos demonstram que na melhor das situações, o poder preditivo alcançado é de $6 \%$ quando essas competências são inseridas como preditores únicos. Já no caso de atuarem junto às competências compartilhadas, não houve qualquer acréscimo derivado da sua entrada no modelo. Esse comportamento das competências individuais permite defender que o êxito do desempenho de equipes de trabalho não resulta da agregação de visões individualizadas sobre a presença de certo repertório de competências. É imprescindível que elas sejam compartilhadas pelos membros, ou que tenha ocorrido o processo de emersão (formação de atributos coletivos a partir de atributos individuais) para que possuam o poder de afetar favoravelmente o desempenho. A respeito da agregação de respostas individuais para representar atributos coletivos, Cooke, Salas, Kiekel e Bell (2004) alertam que o uso dessa estratégia não captura o compartilhamento, característica central estruturante dos fenômenos típicos das equipes. Já com relação aos efeitos sobre os resultados do trabalho coletivo, Le Boterf (2003) aponta que as equipes ou outros coletivos de trabalhadores estarão mais habilitados a enfrentar os desafios que o trabalho lhes impõe se forem exitosos da conjugação de competências. Ainda descreve as competências coletivas como competências de rede, denominação que especifica o fato de não serem apenas agregados coletivos. Assim, a literatura da área já defende o papel prioritário das competências compartilhadas para o alcance de resultados.

Em relação às competências da equipe e os impactos atrelados a sua ocorrência, a segunda hipótese (H2) defende que o maior o compartilhamento resulta em melhor desempenho. Os dados obtidos revelaram que, de fato, as competências de equipe, quando operacionalizadas a partir da similaridade, possuem o poder de predizer uma parcela significativa do desempenho avaliado pelo líder (aproximadamente 22,0\%). Esse achado reforça a afirmação antes feita quanto à centralidade do compartilhamento no estudo das competências de equipe, se comparado com o resultado encontrado na testagem de $\mathrm{H} 1$, que teve como foco as competências individuais.

O leitor deve estar se perguntando qual o significado da porcentagem de explicação alcançada. Para responder a essa indagação é importante resgatar a variável critério predita: o desempenho da equipe avaliado pelo líder. Desse modo, o valor obtido significa que ao redor de $20 \%$ da avaliação que o líder faz sobre o desempenho das equipes sob seu comando resulta do quanto esses integrantes compartilham a visão sobre as competências que a sua equipe detêm.

Buscando o sustento teórico para esse mesmo achado, observa-se que ele vai ao encontro do posto pela literatura da área, que defende a centralidade do compartilhamento de competências dos membros das equipes em relação a diversos atributos. São apontados como exemplos a cooperação, comunicação, tomada de decisão e liderança (Puente-Palacios \& González-Romá, 2013). Não é suficiente, portanto, para o desempenho de equipe, que os membros dominem as competências necessárias para a realização da tarefa. É preciso ir além, pois os dados desse estudo mostram que é imprescindível a ocorrência de um elevado compartilhamento. Os resultados das pesquisas realizadas por Bole, Fink e Prašnikar (2016) assim como os do estudo de Hauland (2008) já ofereceram sustento empírico a essa associação defendida, uma vez que os achados desses autores evidenciaram associações positivas entre cognições compartilhadas e melhores desempenho das equipes.

A terceira hipótese do estudo (H3) assevera que o maior poder preditivo decorre das competências compartilhadas pela equipe se comparado ao das competências individuas agregadas. Na testagem dessa hipótese foi observado, em um primeiro momento, que após a entrada das competências coletivas, a entrada das competências individuais não agregavam poder explicativo ao modelo. Em um segundo momento, todavia, foi realizada inversão da entrada, inserindo no primeiro passo as competências individuais o que demostrou um poder preditivo de escassa magnitude (aproximadamente 6\%). Desse modo, os dados sugerem que o desempenho de equipes está alavancado no fato dos seus membros apresentarem níveis similares de competências necessárias para a realização das tarefas e manutenção do grupo. Esse mesmo dado permite afirmar paralelamente que para o trabalho em equipes ser exitoso, não basta um 
ou outro membro possuir as competências necessárias. Elas devem ser compartilhadas.

Após investigar o papel preditor das competências individuais e coletivas em relação ao desempenho da equipe, conforme julgamento do líder, investigou-se o papel preditivo dessas mesmas variáveis em relação o desempenho avaliado por um indicador duro, no caso, o tempo-resposta apesentado pelas equipes em atividades de simulação. De maneira surpreendente, os resultados revelaram ausência de qualquer poder explicativo. Esse achado inesperado leva a buscar justificativas plausíveis para a sua ocorrência.

Analisando o comportamento do critério adotado (temporesposta, mensurado em segundos), observa-se a escassa variância. As medidas de tendência central e dispersão revelam que o desvio padrão esteve situado ao redor de 26 $($ média $=134,57 ;$ moda $=137)$ e o valor máximo foi 181 segundos. Isso demonstra presença de elevada similaridade nas respostas, o que significa que há escassa variância para ser explicada. Adicionalmente, os dados de distribuição dessa variável revelaram que $50 \%$ das equipes levaram até 137 segundos (mediana), sendo, portanto, abaixo do tempo-resposta definido por regulamentações de segurança aeroportuária como máximo (180 segundos ou 3 minutos). Uma vez que há uma predefinição do tempo máximo que as equipes podem levar para emitir a resposta nos exercícios de simulação e que a não observância dessa determinação traz impactos para a equipe, pois, se recorrente, ela pode significar a não certificação aeroportuária dentro de limites segurança aceitos, entende-se que há um esforço generalizado por desempenhar abaixo do teto do tempo-resposta. Assim, a escassa variabilidade nesse quesito é uma característica presente nessas equipes e ela é buscada por ser considerada benéfica, uma vez que sinaliza êxito no desempenho. Esse conjunto de evidencias nos obriga a reconhecer que a escolha do tempo resposta como indicativo de desempenho não constituiu uma decisão adequada, pois ele apresenta pouca variabilidade. Desse modo alerta-se o leitor quanto a necessidade de analisar cuidadosamente os critérios de desempenho adotados, pois, eles devem possuir variabilidade suficiente, de sorte a permitir testar as associações em tela. Ainda quanto a esse resultado, destaca-se que indicadores duros de desempenho não devem ser vistos como inadequados ou menos confiáveis. Apenas é necessário tomar o cuidado de analisar previamente o seu comportamento buscando verificar a pertinência do seu uso para os fins que se espera.

O conjunto de achados derivados do estudo realizado permite também tecer algumas considerações de natureza prática. Conforme apontam Carbone et al. (2006), ao tratar dos patrimônios de conhecimento, que são a nova riqueza das organizações, as competências dos funcionários constituem uma das três dimensões de ativos intangíveis do conhecimento e que deveriam ser contabilizadas no balanço patrimonial da organização dada a importância que exercem para o bom funcionamento da empresa, tornando-se muitas vezes o diferencial competitivo das organizações.

Dessa maneira, ter funcionários competentes é importante, mas como visto nesse estudo para contextos organizacionais nos quais o trabalho em equipe é adotado, ser competente isoladamente não é o suficiente. É preciso que a equipe seja competente. Portanto, é necessário que haja o compartilhamento de competências entre os membros da equipe. Nesse sentido e tendo em vista a natureza do estudo realizado - que buscou a predição do desempenho mediante um modelo explicativo no nível meso -, as derivações que oportuniza também estão alinhadas com esse nível. Sugeremse ações de treinamento e desenvolvimento, que favoreçam o surgimento de cognições compartilhadas nessas equipes, as quais podem focar no conhecimento sobre as tarefas da equipe e a sua execução, no conhecimento dos membros, e nas atitudes e crenças relacionadas ao trabalho coletivo. Os treinamentos, portanto, para essas equipes, além de conter conteúdos e atividades que visem a sanar lacunas de competências e manter a proficiência adquirida, devem ser planejados de sorte a criar espaços de aprendizagem que favoreçam o surgimento das cognições compartilhas. A esse respeito, ainda é importante destacar que a convivência proporcionada pelos treinamentos coletivos pode favorecer o surgimento de atributos coletivos diversos que, ao serem colocados a serviço da equipe, podem favorecer o desempenho e a busca pelo bem-estar dos membros.

Apesar de o estudo realizado trazer contribuições, ele também apresenta algumas fragilidades. Uma delas é o fato de ter sido encontrados resultados significativos exclusivamente para o caso de variáveis coletadas mediante a aplicação de questionários. Dessa maneira, permanece a dúvida sobre o fato de identificar relações similares caso outros mecanismos de levantamento de informações tivessem sido adotados. Adicionalmente, o fato dos dados terem sido recolhidos no mesmo momento pode ser considerada uma segunda fragilidade. Ou seja, dados relativos às variáveis antecedentes e consequentes foram levantados simultaneamente, fato que pode trazer padrões similares de variação, em decorrência de um vento externo não controlado. Ainda assim, parece pouco provável a ocorrência desse fato, tendo em vista as diferenças vistas nas correlações entre as variáveis do estudo.

Apesar das limitações apresentadas, o estudo possui também pontos fortes. O primeiro está na constatação empírica de que as competências podem ser legitimamente tratadas como atributo coletivo. Um segundo aspecto a destacar é o fato do compartilhamento de cognições, tratado na pesquisa como competências de equipe ou competências coletivas, ter mostrado poder de influência direta e significativa em relação ao desempenho das equipes pesquisadas. O terceiro consiste na relação estabelecida entre competências da equipe e desempenho avaliado por meio de julgamento feito pelo líder. A importância dessa contribuição está sustentada também nas afirmações de Brandão (2009) que destacou a existência de apenas uma pesquisa nacional na qual as competências requeridas estavam relacionadas a outras variáveis organizacionais.

Consoante com as constatações oferecidas pela pesquisa empírica relatada é necessário reconhecer que as incertezas relacionadas ao poder explicativo das competências compartilhadas são inúmeras, porém, os primeiros passos foram dados. Instam-se, por essa razão, os pesquisadores a oferecerem contribuições a este campo da ciência e darem luz a um fenômeno tão escassamente estudado no Brasil e no exterior. 


\section{Referências}

Bole, V., Fink, L. \& Prašnikar, J. (2016). Customer focus competencies and the dynamics of project teams. Total Quality Management \& Business Excellence, 27(1-2), 198-214.

Brandão, H. P. (2009). Aprendizagem, contexto, competência e desempenho: Um estudo multínivel (Tese de Doutorado não publicada). Universidade de Brasília, Brasil).

Brandão, H., Borges-Andrade, J. E., Puente-Palacios, K. E., \& Laros, J. A. (2012). Relationships between learning, context and competence: A multilevel study. Brazilian Administration Review (BAR), 9, 1-22.

Bruno-Faria, M. F., \& Brandão, H. P. (2003). Competências relevantes a profissionais de T\&D de uma organização pública do Distrito Federal. Revista de Administração Contemporânea, 3, 35-56.

Burke, M. J., \& Dunlap, W. P. (2002). Estimating interrater agreement with the average deviation index: A user's guide. Organizational Research Methods, 5, 159-172.

Cannon-Bowers, J., \& Salas, E. (2001). Reflection on shared cognition. Journal of Organizational Behavior, 22, 195-202.

Cannon-Bowers, J. A., Tannenbaum, S. I., Salas, E., \& Volpe, C. E. (1995). Defining team competencies and establishing team training requirements. In R. Guzzo \& E. Salas (Eds.), Teams effectiveness and decision making in organizations (pp. 333380). San Francisco: Jossey Bass.

Carbone, P. P., Brandão, H. P., Leite, J. B. D., Vilhena, M. P. (2006). Gestão por Competência e gestão do conhecimento. Rio de Janeiro: Editora FGV.

Chan, D. (1998). Functional relations among constructs in the same content domain at different levels of analysis: A typology of compositions models. Journal of Applied Psychology, 83, 234-246.

Cooke, N., Salas, E., Cannon-Bowers, J., \& Stout, R. (2000). Measuring team knowledge. Human Factors, 42, 151-173.

Cooke, N., Salas, E., Kiekel, P., \& Bell, B. (2004). Advances in measuring team cognition. In E. Salas \& S. Fiore (Eds.), Team cognition: Understanding the factors that drive process and performance (83-106). Washington, DC: American Psychological Association.

Durand, T. (2006). L'alchimie de la compétence. Revue Française de Gestion, 160, 261-291.

Fiore, S., \& Schooler, J. (2004). Process mapping and shared cognition: Teamwork and the development of shared problems models. In E. Salas \& S. Fiore (Eds), Team cognitions: Understanding the factor that dive process and performance (pp 133-152). American Psychologycal Association: Washington.

Gilbert, D. T., Fiske, S. T., \& Lindzey, G. (1998). The Handbook of social psychology (4th Edition). New York: McGraw-Hill.

Hackman, R. (2002). Leading teams: Setting the stage for great performances. Boston: Harvard Business School Press.
Hauland, G. (2008). Measuring individual and team situation awareness during planning tasks in training of en route air traffic control. The International Journal of Aviation Psychology, 18(3), 209-304.

Hertel, G., Konradt, U., \& Voss, K. (2007). Competencies for virtual teamwork: Developmentand validation of a web-based selection tool for members of distributed teams. European Journal of Work and Organizational Psychology, 15(4), 477504.

James, L., Choi, C., Ko, Ch., McNeil, P., Minton, M. Wright, M. A., \& Kim, K. (2008). Organizational and psychological climate: A review of theory and research. European Journal of Work and Organizational Psychology, 17, 5 - 32

Kaplan, S., Laport, K.,\& Waller, M. J. (2013). The role of positive affectivity in team effectiveness during crises. Journal of Organizational Behavior, 34, 473-491.

Klein, K. J. \& Kozlowski, S. W. J. (2000). A multilevel approach to theory and research in organizations. In K. Klein \& S. Kozlowski (Eds), Multilevel theory, research, and methods in organizations: Foundations, extensions, and new directions (pp. 3-88). San Francisco: Jossey-Bass.

Kozlowski, S., \& Chao, G. (2012). Macrocognition, team learning, and tam knowledge: Origins, emergence, and measurement. In E. Salas, S. Fiore, \& M. Letsky (Eds), Theories of team cognition: Cross-disciplinary perspectives (pp 19-48). New York: Tylor \& Francis Group.

Le Boterf, G. (2003). Desenvolvendo a competência dos profissionais ( $3^{\mathrm{a}}$. Ed.). Porto Alegre: Artmed.

Menard, S. (1995). Applied logistic regression analysis (Thousand Oaks: Sage University paper series on quantitative applications in the social sciences). Recuperado de http://books.google. com.br/books?id=EAI1QmUUsbUC\&printsec=frontcover\& $\mathrm{dq}=$ applied + logistic + regression + analysis + menard\&hl=en\&s $\mathrm{a}=\mathrm{X} \& \mathrm{ei}=8 \mathrm{JmbU}$ 9rKCsmjsQSm7oCQAQ\&ved=0CBsQ6AE $\mathrm{wAA} \# \mathrm{v}=$ onepage $\& \mathrm{q}=$ applied $\% 20 \operatorname{logistic} \% 20$ regression $\% 20$ analysis $\% 20$ menard $\& \mathrm{f}=$ false

Puente-Palacios, K. E., \& Portmann, A. C. (2009). Equipes de trabalho: Fundamentos teóricos e metodológicos da mensuração de seus atributos. Revista Avaliação Psicológica - IBAP, 8, 369-379.

Puente-Palacios, K., \& González-Romá, V. (2013). Gestão de equipes de trabalho. In L. De O. Borges \& L. Mourão (Orgs.), O trabalho e as organizações: Atuações a partir da Psicologia (pp. 311-338). Porto Alegre: Artmed.

Puente-Palacios, K., Martins M do C., \& Palumbo, S. (2016). Desempenho de equipes: Desenvolvimento de uma medida. PSICO-USF, 21(3). 513-525.

Rentsch, J. \& Woeher, D. (2004). Quantifying congruence in cognition: Social relations modeling and team member schema similarity. In E. Salas \& S. Fiore (Eds.), Team cognitions: Understanding the factor that dive process and performance. (pp. 11-31). Washington: American Psychologycal Association.

Salas, E., Cooke, N., \& Rosen, M. (2008). On teams, teamwork, and team performance: Discoveries and developments. Human Factors, 50, 540-547. 